\title{
Pregnancy in Takayasu arteritis - maternal and fetal outcome
}

\author{
Kavitha Garikapati*, Lakshmi Narayana Kota, Prabha Devi Kodey
}

Department of Obstetrics and Gynaecology, NRI Medical College and General Hospital, Chinakakani-522503, Mangalagiri Mandal, Guntur District, Andhra Pradesh, India

Received: 24 May 2016

Revised: 21 June 2016

Accepted: 04 July 2016

\section{* Correspondence:}

Dr. Kavitha Garikapati,

E-mail: kavithagarikapati4@gmail.com

Copyright: () the author(s), publisher and licensee Medip Academy. This is an open-access article distributed under the terms of the Creative Commons Attribution Non-Commercial License, which permits unrestricted non-commercial use, distribution, and reproduction in any medium, provided the original work is properly cited.

\section{ABSTRACT}

Background: Takayasu arteritis is a rare medical disorder of primary vasculitis of unknown etiology. It affects reproductive age women. It is rare disease and associated with serious maternal and fetal complications and long term morbidity.

Methods: Retrospective analysis of patients with diagnosed Takayasu arteritis, to know the impact of disease on maternal status and evaluate fetal outcome. The objective of this study was to know the maternal and fetal outcome in pre-diagnosed cases of Takayasu arteritis. The necessity of accurate measurement of pulse and blood pressures in all the limbs in a suspected case of hypertension in antenatal women at any period of gestation and TYPE the disease accordingly. 3. To evaluate the typing of TA on maternal and fetal outcome.

Results: All the 4 patients with TA had medical complication like hypertension in the form of chronic hypertension and pre eclampsia that needed good monitoring of BP in all 4 limbs.

Conclusions: As the typing of disease increased, more medical and obstetric complications were noticed.

Keywords: Takayasu arteritis, Hypertension, Superimposed preeclampsia, Renal artery stenosis, Aortoarteritis, Cardiomyopathy

\section{INTRODUCTION}

Takayasu arteritis is a chronic inflammatory arteriopathy affecting large vessels, predominantly the aorta and its main branches. ${ }^{1,2}$ Pregnancy is a favourable state if the disease is in remission state. It is a rare disease, relatively more common in South East Asian countries. ${ }^{3}$ It has a higher preponderance for women in reproductive age groups, in the $2^{\text {nd }}$ and $3^{\text {rd }}$ decades of life. ${ }^{4-6}$ The etiology though speculative, literature suggests autoimmune basis. ${ }^{2,7,8}$ Clinical presentation varies depending on the sites of constriction of blood vessels and so the typing. ${ }^{9,10}$ Optimal management of pregnancy in this condition cannot be standardized due to rarity and variation in disease profile.

\section{METHODS}

4 cases of pre-diagnosed Takayasu arteritis were retrospectively analyzed.

All cases were booked at NRIGH gynaec OPD at 6, 18, 14 and 26 weeks gestation, were checked for asymmetry of pulse rates and disparity in BP in all limbs. Advised obstetric USG, Doppler of renal arteries, 2D ECHO and ECG at their first visit and nephrologist, cardiologist and ophthalmologist consultation were taken. At each visit, peripheral pulses, BP was measured in all 4 limbs and ECHO was repeated at monthly intervals and under regular cardiologist follow-ups. All the patients were kept on tablet labetalol $100 \mathrm{mg} / 1 / \mathrm{bd}$, Antiplatelet were stopped at $8^{\text {th }}$ month gestation. 
RESULTS

Table 1: Age distribution.

\begin{tabular}{|l|l|}
\hline Age in years & No. of cases \\
\hline $20-25$ years & 1 \\
\hline $26-30$ years & 2 \\
\hline $31-35$ years & 1 \\
\hline
\end{tabular}

Table 2: Gravida status.

\begin{tabular}{|ll|}
\hline Gravida & No. of cases \\
\hline Primigravida & 1 \\
\hline $\begin{array}{l}\text { G2P1L0D1 with previous neonatal } \\
\text { death }\end{array}$ & 1 \\
\hline G3A2 with previous 2 abortions & 2 \\
\hline
\end{tabular}

Age at diagnosis: All the cases were diagnosed between 20-25 years with various symptoms of dyspnea, peripartum cardiomyopathy, early onset hypertension, asymmetrical pulses and BP. Diagnosed by 2D ECHO, Doppler of renal arteries, coronary and aortogram. All these cases were managed by cardiologist.

Table 3: Typing of disease.

\begin{tabular}{|ll|}
\hline TYPE of disease & No. of cases \\
\hline Type I & 0 \\
\hline Type II & 0 \\
\hline Type III & 2 \\
\hline Type IV & 0 \\
\hline Type V & 2 \\
\hline
\end{tabular}

Table 4: Duration of disease in years before pregnancy and typing.

\begin{tabular}{|lll|}
\hline Type of disease & No. of cases & Type of disease \\
\hline$<5$ years & 2 & III \\
\hline $5-10$ years & 0 & 0 \\
\hline$>10-15$ years & 2 & V \\
\hline
\end{tabular}

\section{Effect of age on typing of disease}

The younger the age at diagnosis and longer the duration of disease, the severe is the typing.

Table 5: Medical complications.

\begin{tabular}{|ll|}
\hline Medical complications & No. of cases \\
\hline Chronic hypertension & 4 \\
\hline Renal artery stenosis & 4 \\
\hline Unilateral with MVP & 1 \\
\hline $\begin{array}{l}\text { Unilateral with subclavian artery } \\
\text { stenosis }\end{array}$ & 1 \\
\hline Bilateral & 1 \\
\hline $\begin{array}{l}\text { Bilateral with aortoarteritis, } \\
\text { cardiomyopathy, PAH }\end{array}$ & 1 \\
\hline
\end{tabular}

All cases had chronic hypertension, renal artery stenosis, renal vessel with other vessels involvement lead to increasing in the type i.e., Type V. 2 cases needed medical intervention- renal artery angioplasty, Renal artery stenting.

\section{Obstetric complications in pregnancy}

Chronic hypertension superimposed preeclampsia - 1, peripartum cardiomyopathy with pulmonary edema - 1 which was shifted to CCU and managed.

Table 6: Mode of delivery and indications.

\begin{tabular}{|ll|}
\hline Mode of delivery & Indications \\
\hline Vaginal route & Nil \\
\hline Caesarian sections & 4 \\
\hline & Breech -2 \\
\hline & Fetal distress -1 \\
\hline & Severe oligamnios -1 \\
\hline
\end{tabular}

All caesarian sections were done for obstetric indications. 1 case went into spontaneous labour at $37+4$ weeks gestation, allowed for vaginal delivery with adequate pelvis but due to fetal distress, emergency caesarian section was done. 3 cases underwent elective caesarian section, all at 38 weeks gestation.

Table 7: Fetal outcome.

\begin{tabular}{|ll|}
\hline Fetal complications & No. of cases \\
\hline Oligamnios & 2 \\
\hline Oligamnios with IUGR & 1 \\
\hline No complication & 1 \\
\hline
\end{tabular}

3 fetuses are born with normal birth weight.

\section{Effect of typing on outcome}

As the severity of typing increased, type V, maternal and fetal complications were increasing in the form of superimposed pre eclampsia on chronic hypertension with oligamnios and IUGR in 1 case, and peripartum cardiomyopathy with pulmonary edema with oligamnios in another case.

\section{Medication history}

All were under anti-hypertensives. Tablet labetalol 100 $\mathrm{mg} / 1 / \mathrm{bd}$. Antiplatelets, diuretics, ACE inhibitors were also given. After confirmation of pregnancy ACE inhibitors and diuretics were stopped.

In my study all the patients were pre-diagnosed with T.A. Any patient presenting with early onset severe hypertension with disparity in pulse rates, suspect coarctation of aorta and Takayasu arteritis. Such cases need to be evaluated with Doppler and aortogram. Careful BP monitoring and medication, regular obstetric 
USG with fetal Doppler will improve maternal and fetal outcome as in my study, which showed good maternal and fetal outcome.

\section{DISCUSSION}

Takayasuarteritis is a rare, chronic, giant cell vasculitis which primarily involves the aorta, its main branches, coronary and pulmonary arteries, named after Japan ophthalmologist, MIKITO TAKAYASU at the $12^{\text {th }}$ Annual meeting of Japan ophthalmology society held in 1908 in Fukuoka. ${ }^{1,2}$ He first reported a case of 21 years old female, whose eye grounds exhibited coronary anastomosis, arteriovenous anastomosis around the papilla due to ischemia of cerebrovascular circulation. Though the usual course is slow, sometimes it is unpredictable. Worldwide Incidence is around 2.5 cases/million, relatively more common in South East Asian countries. ${ }^{3}$ More prevalent among young women in $2^{\text {nd }}$ and $3^{\text {rd }}$ decades of life, so called "young female arteritis". ${ }^{4-6}$ Even though the etiology is not known the literature suggests autoimmune basis., ${ }^{27,8}$ The 5 year survival rate is $90 \%$. There is high incidence of residual morbidity. The disease causes various clinical conditions depending on the sites of constriction such as arm claudication, decreased arterial pulses, visual loss, stroke, aortic regurgitation, Hypertension, congestive cardiac failure. ${ }^{9,10}$ Hypertension is seen in $90 \%$ cases of Takaysuarteritis. ${ }^{11}$ In my study, all the 4 patients (100\%) had hypertension.

According to the American college of rheumatology 1990 criteria. For the diagnosis of Takayasu arteritis, 3 out of 6 criteria must be fulfilled to make the diagnosis of Takayasuarteritis. $^{12}$

- Age under 40 at disease onset

- Claudication of extremities

- Decreased brachial arterial pulses

- Systolic blood pressure difference of more than 10 $\mathrm{mmHg}$, between arms

- Bruit over subclavian arteries or the aorta

- Angiogram abnormalities: occlusion or narrowing of entire aorta, its primary branches or large arteries in the proximal upper or lower extremities.

If these criteria are satisfied, there is $90.5 \%$ sensitivity and $97.8 \%$ specificity.

\section{Criteria for active disease $e^{13}$}

- Features of vascular ischemia or inflammation (such as vascular pain (carotodynia), claudication, diminished or absent pulses, bruit), asymmetric blood pressures in either upper or lower limbs or both

- $\quad$ Elevated ESR

- Systemic features, such as fever, musculoskeletal pains (without any cause identified).

\section{Criteria for remission}

- Complete resolution or stabilization of all clinical features

- Fixed vascular lesions.

According to new angiographic classification of Takayasu arteritis, five types of disease can be identified that depends on the angiographic findings and vessel involvement. $^{14}$

- Type-I: involves the branches from aortic arch

- $\quad$ Type-II (a): involves the ascending aorta, aortic arch and its branches

- Type-II (b): involves the ascending aorta, aorta arch and its branches and thoracic descending aorta

- Type-III: involves thoracic descending aorta, abdominal aorta and or renal arteries

- Type-IV: involves abdominal aorta, and or renal arteries

- Type-V: Combined features of type IIB and IV.

Additionally, involvement of the coronary and pulmonary arteries should be indicated as $\mathrm{C}(+)$ or $\mathrm{P}(+)$. This classification allows comparison of patient's characteristics according to the involved vessels and they are helpful for planning surgery, but they offer little information of the prognosis.

Pregnancy with Takayasu arteritis have been reported to have a 13 fold higher rate of obstetric complications compared to normal pregnancy. ${ }^{15}$ Earlier literature suggests that most of the pregnant patients with Takayasu Arteritis reached successfully till term and had vaginal deliveries with good fetal outcome with type-I and type II. Incidence of secondary hypertension and IUGR were low in these patients. Poor perinatal outcome was usually seen in Type III, IV, V.

Maternal and fetal complications like pre-eclampsia, preterm delivery, IUFD, IUGR, secondary hypertension, Takayasu retinopathy, have been reported with higher incidence. ${ }^{16-18}$ Involvement of abdominal aorta and renal vessels could be the cause for higher incidence of IUGR $(29.5 \%)$ and poor perinatal outcome. Pulmonary hypertension is a common feature with high maternal mortality. ${ }^{19}$ Maternal death by exacerbated hypertension and its complications. ${ }^{18}$ Abruption, Cardiac failure, described in 2 studies. ${ }^{20}$ The rare, potentially fatal maternal complications such as aortic aneurysm, cerebral haemorrhage, has also been reported. ${ }^{21,22}$ As my study had a case of renal artery stenosis along with concomitant subclavian artery stenosis, another case has been reported by Nalini et al. ${ }^{23}$ It is interesting to note that aortoarteritis has been postulated to be a precursor to APLA syndrome. ${ }^{24,25}$ Perinatal morbidity and mortality: In the evaluation of 115 cases from different centers, the abortus rate was $15.6 \%$,premature birth rate $9.5 \%$,IUGR rate $17 \%$, neonatal death 1 case. $^{26-28}$ Vaginal delivery 
could be indicated in type I and type IIa. Epidural anaesthesia provides stable hemodynamics and pain relief during labour and delivery. Second stage of labour should be cut short by instrumental delivery. For LSCS also, choice of anaesthesia is epidural anaesthesia because regional anaesthesia is associated with sympathetic blockade and subsequent drop in BP specially harmful in a patient with compromised regional circulation due to stenosed arteries. ${ }^{20}$ Epidural anaesthesia is associated with gradual onset of sympathetic block and decrease in BP. Epidural block ensures complete pain relief which helps in smooth control of BP in the intraoperative and postoperative period. In my study all were delivered by caesareans section for obstetric indications under epidural anaesthesia.

\section{Prognosis of Takayasuarteritis in pregnancy}

Long term prognosis is good. Approximately 20\% have monophasic self-limiting disease.

\section{Differential diagnosis}

Marfan's and Ehler Danlos syndrome, Tuberculosis, some autoimmune conditions like SLE, temporal arteritis, cogan's syndrome, behcets disease, sarcoidosis, stroke. Angiography remains the gold standard for the diagnosis.

\section{Treatment principles}

Control of hypertension, prevention of renal failure and arterio plastic approach to stenosed vessels. ${ }^{11}$

\section{Management}

- Corticosteroids

- Immunosuppressive therapy, and

- Angioplasty

- Bypass surgeries. Cortico steroids are the main stay of therapy with remission rate up to $60 \%$. $^{29-31}$

According to EULAR. European league against rheumatism, starting dose of glucocorticoids = $1 \mathrm{mg} / \mathrm{kg} /$ bodyweight for 4 weeks and then taper off.

\section{Indications for reconstructive vascular surgery}

- Cases with critical renovascular hypertension

- Severe claudication

- Critical stenosis of cerebral vessels

- Ischemic crisis

- Aortic regurgitation.

\section{Methods of surgery}

- Ascendo carotid bypass

- Thoraco iliac bypass
- Per-cutaneous trans-luminal angioplasty and stenting or bypass surgery is the most common palliative treatment. $^{29,30}$

\section{Learning points from literature}

A careful thought has to be given to the typing of the disease Patient diagnosed for the first time during pregnancy may have unpredictable complications even if the disease appears to be stable. So, alertness at all times with preparation of timely intervention is needed. The importance of careful palpation of all peripheral pulses cannot be over emphasized. Regular ANC and cardiac visits, timely admission, close monitoring, and a multidisciplinary approach is mandatory.

\section{CONCLUSION}

Takayasu arteritis should be suspected as one of the differential diagnosis when a young female presents with hypertension. As delayed detection and secondary hypertension are poor prognostic factors for Takayasu Arteritis, attention to not only accurate B.P measurement and disparity in both upper limbs and lower limbs, but also to check any disparity in all peripheral pulses for early diagnosis of Takayasu's arteritis. BP should be strictly controlled for favourable maternal and fetal outcome. All women should be subjected for regular growth scans and fetal Doppler performed from $20^{\text {th }}$ week period of gestation. Type of Takayasu arteritis affects the course of disease and maternal and fetal prognosis.

Funding: No funding sources

Conflict of interest: None declared

Ethical approval: The study was approved by the Institutional Ethics Committee

\section{REFERENCES}

1. Wike WS. Large vessel vasculitis (giant cell arteritis, Takayasuarteritis. Bailliers Clin Rheumatol. 1997;11(2):285-313.

2. Numano F. Hereditary factors of Takayasuarteritis. Heart Vessels. 1992;7:68-72.

3. Numano F, Okawara $M$, Inomata $H$, et al. Takayasu'sarteritis. Lancet. 2000;356:1023-5.

4. Sharma BK, Sagar S, Chugh KS, Sakhuja V, Rajachandran A, Malik N. Spectrum of renovascular Hypertension in the young in North India: a hospital based study on occurrence and clinical features. ANGIOLOGY. 1985;36(6):370-8.

5. Jain S, Kumara S, Ganguly NK, Sharma BK. Current status of Takayasuarteritis in India. Int $\mathrm{J}$ Cardiol. 1996;54:111-6.

6. Koide K. Takayasuarteritis in Japan. Heart Vessels.1992;7:48-54.

7. Ueda H, Saito Y, Ito I, Yamaguchi H, Takeda T. Immunological studies of aortitis syndrome. Jpn Heart J. 1967;8:4-18. 
8. Kimura A. Kimura H. Date Y. Comprehensive analysis of HLA genes in Takayasuarteritis in Japan. Int J Cardiol. 1996;54:61-9.

9. Sato EL. Hatta FS, Levy-Neto M. Demographic, clinical and angiographic data of patients with Takayasuarteritis in Brazil. Int $\mathrm{J}$ Cardiol. 1998;66:67-70.

10. Mohamed AP, Michael LC, Mikhail E. A case of Takayasuarteritis causing sub clavian steal and presenting as syncope. J Emer Med. 2011;40:158-61.

11. Langford AC, Fauci AS. The Vasculitis Syndrome S.In;Lango LD, Kasper DL,Jameson JL,Fauci AS, ,Hauser SL ,LoscalZo J .Eds Harrison's principles of Internal Medicine $18^{\text {th }}$ edition. Mc Graw Hill; 2015.

12. Arend WP, Michel BA, Bloch DA, Hunder GG, Calabrese LH, Edworthy SM, et al. The American College of Rheumatology 1990 criteria for the classification of Takayasuarteritis. Arthritis Rheum. 1990;33(8):1129-34.

13. Kerr G. Takayasu's arteritis . Curropin Rheumtol. 1994;6:32-8.

14. Moriwaki R, Noda M, Yajima M, Sharma BK, Numano F. Clinical manifestations of Takayasuarteritis in India and Japan - new classification of angiographic findings, angiology. 1997;48:369-79.

15. Comarmond C, Mirault T, Biard L, Nizard J, Lambert M, Werchia B, et al. Takayasuarteritis and pregnancy. Arthritis Rheumatol. 2015;67(12):32629.

16. Mandal D, Mandal S, Dattaray C, Banerjee D, Ghosh P. Takayasuarteritis in pregnancy in an analysis from eastern India, Arch Gynaecolobstet. 2012;285(3):567-71.

17. De Jesius GR, d'liveira LE, des santos FC, Rodaigues G, Klumb EM, de Jesus NR, et al. Pregnancy may aggravate arterial hypertension in women with Takayasuarteritis. $1^{\text {st }}$ Med Assoc J. 2012;14(2):724-8.

18. Suri V, Aggarwal N, Keepanasseril A, Chopra S, Vijay vergiya R, Jain S. Pregnancy and Takayasuarteritis: a single centre experience from North India. J Obstet Gynaecol Res. 2010;36(3):51924.

19. Wang X, Dang A, Chen B, LVN, Lin Q. Takayasu arteritis associated pulmonary hyptertension. J Rheumatol. 2015;42(3):495-503.
20. Ishikawa K, Matsumura S. Occlusive thrombo arthropathy (Takayasu's disease) and pregnancy clinical course and management of 33 pregnancies and deliveries. Am J Cardiol. 1982;50(6):1293-1300.

21. Umeda Y, Mori Y, Takagi H, Iwata H, FukumatoY, Hirose H. Abdominal aortic aneurysm related to Takayasuarteritis during pregnancy. Heart Vessels 2004;19:155-6.

22. Ishikawa Tornioka N, Hirose K, Abe E, Miyamoto $\mathrm{N}$, Araki K, Nomura R, et al. Indications for peripartum aortic pressure monitoring in Takayasu'sdisease. A patient with past history of intra-partum cerebral haemorrhage. Jpn Heart J. 1998;39:255-60.

23. Nalini S, Santa SA. Takayasuarteritis with Bilateral renal artery stenosis and left subclavian artery stenosis in pregnancy. J clin Diagn Res. 2015;9(9):Q D07-8.

24. Dhaon P, Das SK, Saran RK, Parihar A. Is aortoarteritis a manifestation of primary antiphospholipid antibody syndrome? Lupus. 2011;20(14):1554-6.

25. Miyaki S, Lockshin MD, Atsumi T, Branch DW, Brey RL, Cervena R, et al. International consensus statement on an update of the classification criteria for definite Anti-phospholipid syndrome (APS). J Thromb Haemost. 2006;4(2):295-306.

26. Castellote RR, Bonet J, Torguet B, Callejas JM, Caralps A. Takayasu'sarteritis as a cause of renovascular hypertension in a non-Asian population. J Hum Hypertens. 1995;9:841-5.

27. Sharma BK, Jain S, Vasistha K. Outcome of pregnancy in Takayasuarteritis. Int $\mathbf{J}$ Cardiol. 2000;75:159-62.

28. Wang V, Wang R. Pregnancy and Takayasuarteritis. Am J Med. 1982;75:597-601.

29. Mason JC. Takayasuarteritis-advances in diagnosis and management. Nat Rev Rheumatol. 2010;6:40615.

30. Brunner J, Feldman BM, Tyrell PN, KuemmerleDeschner JB, Zimmer hackl LB, Gassner I, et al. Takayasuarteritis in children and adolescents. Rheumatology. 2010;49:1806-14.

31. Johnston SL, Lock RJ, Gompels MM. Takayasuarteritis: a review. J Clin Pathol. 2002;55:481-6.

Cite this article as: Garikapati K, Kota LN, Kodey PD. Pregnancy in Takayasu arteritis maternal and fetal outcome. Int J Reprod Contracept Obstet Gynecol 2016;5:2596-2600. 